\title{
Understanding of morphometric features for adequate water resource management in arid environments
}

\author{
Mohamed Elhag ${ }^{1}$, Hanaa K. Galal ${ }^{2,3}$, and Haneen Alsubaie ${ }^{2}$ \\ ${ }^{1}$ Department of Hydrology and Water Resources Management, Faculty of Meteorology, Environment \& Arid Land \\ Agriculture, King Abdulaziz University, Jeddah 21589, Saudi Arabia \\ ${ }^{2}$ Biological Sciences Department, Faculty of Science, King Abdulaziz University, Jeddah 21589, Saudi Arabia \\ ${ }^{3}$ Botany Department, Faculty of Science, Assiut University, Asyut, Egypt \\ Correspondence to: Mohamed Elhag (melhag@kau.edu.sa)
}

Received: 15 March 2017 - Discussion started: 19 April 2017

Revised: 4 July 2017 - Accepted: 6 July 2017 - Published: 10 August 2017

\begin{abstract}
Hydrological characteristics such as topographic parameters, drainage attributes, and land use/land cover patterns are essential to evaluate the water resource management of a watershed area. In the current study, delineation of a watershed and calculation of morphometric characteristics were undertaken using the ASTER global digital elevation model (GDEM). The drainage density of the basin was estimated to be very high, which indicates that the watershed possesses highly permeable soils and low to medium relief. The stream order of the area ranges from first to sixth order, showing a semi-dendritic and radial drainage pattern that indicates heterogeneity in textural characteristics, and it is influenced by structural characteristics in the study area. The bifurcation ratio $(\mathrm{Rb})$ of the basin ranges from 2.0 to 4.42 , and the mean bifurcation ratio is 3.84 in the entire study area, which signifies that the drainage pattern of the entire basin is controlled much more by the lithological and geological structure. The elongation ratio is 0.14 , which indicates that the shape of the basin has a narrow and elongated shape. A land use/land cover map was generated by using a Landsat- 8 image acquired on 10 August 2015 and classified to distinguish mainly the alluvial deposit from the mountainous rock.
\end{abstract}

\section{Introduction}

Soil studies that include interpolation techniques focus mainly on either inverse distance weighting (IDW) or Kriging methods, followed by accuracy assessment. Gotway et al. (1996) found that the IDW method generated more ac- curate results for mapping soil organic matter and soil $\mathrm{NO}_{3}$ levels. Wollenhaupt et al. (1994) compared these two interpolation techniques and concluded that IDW was more accurate for mapping P and K levels soil. Mueller et al. (2004) observed that for the optimal parameters of the method, the accuracy of IDW interpolation generally equaled or exceeded the accuracy of Kriging at each scale of measurement. However, other scholarly works observed Kriging to be more accurate for the interpolation of soil attributes. Leenaers et al. (1990) found the Kriging interpolation method to be more accurate in comparison to IDW for mapping soil $\mathrm{Zn}$ content.

Further studies have compared Kriging, IDW and radial basis function interpolation techniques in soil science. Schloeder et al. (2001) observed that ordinary Kriging and inverse distance weighting were similarly accurate and effective methods, while thin-plate smoothing splines with tension were not. Weller et al. (2007) concluded not only that the predications for Kriging were not satisfied by the Kriging method but also that it was as good as any other radial base function interpolation.

Hydrological parameters are essential for adequate water resource management plans. Morphometric characteristics are used to investigate watershed delineation, site selection in water recharge and discharge, runoff modelling and other geomorphological studies (Sreedevi et al., 2013; Elhag, 2015). GIS helps with a wide variety of basin characterization and evaluation applications under different terrain conditions (Pankaj and Kumar, 2009; Magesh et al., 2011).

Digital elevation model (DEMs), such as the ASTER global digital elevation model (GDEM) (USGS, USA), are 
of key importance in various extractions of geohydrological parameters of a watershed. Several parameters including slope, aspect, stream network, and upstream flow areas can be retrieved from the DEM characterization (Grohmann et al., 2007; Elhag, 2015). Reliable results of implementing remote sensing and GIS-based morphometric evaluation using ASTER GDEM data have been reported in numerous scholarly works on watershed characterization (Farr and Kobrick, 2000; Panhalkar, 2014; Elhag, 2015).

The main aim of the present study is to identify and investigate various drainage attributes for geometrical evaluation of the Yalamlam Basin for sustainable rainwater harvesting management and conservation of water resources.

\section{Materials and methods}

\subsection{Study area}

The Wadi Yalamlam Basin is located about $125 \mathrm{~km}$ southeast of the city of Jeddah and is bounded by latitudes $20^{\circ} 26^{\prime}$ and $21^{\circ} 8^{\prime} \mathrm{N}$ and longitudes $39^{\circ} 45^{\prime}$ and $40^{\circ} 29^{\prime} \mathrm{E}$ (Fig. 1). The Wadi Yalamlam Basin drains a large catchment area of about 180000 ha. The boundary of the lower part of the basin is enlarged to include nearly all of the flat area in the downstream part. The Wadi Yalamlam Basin is initiated from the high-elevation Hijaz escarpment, with a mean annual rainfall of about $140 \mathrm{~mm}$. The basin elevations varies greatly from upstream and downstream parts and range between 2850 and $25 \mathrm{~m}$ (a.s.l.) respectively. The main course of Wadi Yalamlam crosscuts highly fractured granitoids and gabbroic and metamorphic rocks until the coastal plain of the Red Sea. The upper and middle parts of the Wadi Yalamlam Basin are covered by dense natural vegetation. The lower part is covered mainly by Quaternary deposits and sand dunes with sparsely scattered, highly altered granitoids and metamorphosed basaltic hills. Several basic dykes are recorded in the lower part of the Wadi Yalamlam Basin. The thickness of Quaternary wadi deposits increases in the lower part (Elhag and Bahrawi, 2017). Regional groundwater flow drains toward the south and southwest, following the general trend of the main wadi channel. The mean monthly maximum temperature is $38^{\circ} \mathrm{C}$ and the mean monthly minimum temperature is $20^{\circ} \mathrm{C}$. The annual rainfall is about $120 \mathrm{~mm}$, falling mainly in the winter season (Elhag, 2016). The thickness of the saturated zone within the aquifer varies from less than $1 \mathrm{~m}$ upstream of Yalamlam to about $30 \mathrm{~m}$ in the Sa'diyah area. The aquifer is generally unconfined, especially in the upper parts of the wadi. Semi-confining conditions may exist in the lower parts, where layers of clay exist. There are about 31 wells in the basin of Wadi Yalamlam, of which 23 are hand-dug wells and the others are drilled.

\subsection{Soil sampling}

Map accuracy and quality depend on the sampling method scale, analytical laboratory errors and prediction errors. Sampling approaches depend on the objectives of the study, which are highly correlated with scale. Random stratified sampling was the adopted sampling design. First, the landscape was divided into smaller areas, named strata, and afterwards 150 random samples were taken from the designated study area (Johnson and Riess, 1982).

\subsection{Physical and chemical soil analysis}

Each individual sample was analyzed separately, and each measurement was repeated three times for the same extract. Thus, the final values of the measured attributes are represented by the mean value of three measurements. Soil samples were analyzed in order to estimate physical analyses (clay, silt and sand).

For standard particle size measurement, the soil fraction that passes through a $2 \mathrm{~mm}$ sieve is considered. Laboratory procedures normally estimate the percentage of sand $(0.05-$ $2.0 \mathrm{~mm})$, silt $(0.002-0.05 \mathrm{~mm})$ and clay $(<0.002 \mathrm{~mm})$ fractions in soils. Soil particles are usually cemented together by organic matter; this has to be removed with $\mathrm{H}_{2} \mathrm{O}_{2}$ treatment. However, if substantial amounts of $\mathrm{CaCO}_{3}$ are present, actual percentages of sand, silt or clay can only be determined by prior dissolution of the $\mathrm{CaCO}_{3}$.

\subsection{Interpolation techniques}

Geostatistical interpolations are based on the assumption that all values of a variable that is measured are the result of a random process. The phrase "random process" does not indicate that all events are independent. More specifically, geostatistical techniques are based on random processes with dependence, otherwise called autocorrelation, and rely on some notion of replication. Repeated observations in nature can result in understanding the variation and uncertainty of natural phenomena, and furthermore in estimating their sequence in space and time. Three interpolation techniques were used for the generation of the prediction maps (interpolation). Inverse distance weighting (IDW), radial basis function (RBF) and ordinary Kriging $(\mathrm{OK})$ methods were compared according to the accuracy of the results (Bahrawi et al., 2016). The following equations were used:

- Spatial distribution (Weibel, 1997):

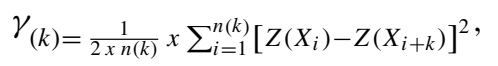

where $n(k)$ is the number of pairs of observation and $Z\left(x_{i}\right)$ the soil property measured in point $x$ and in point $x+k$. 


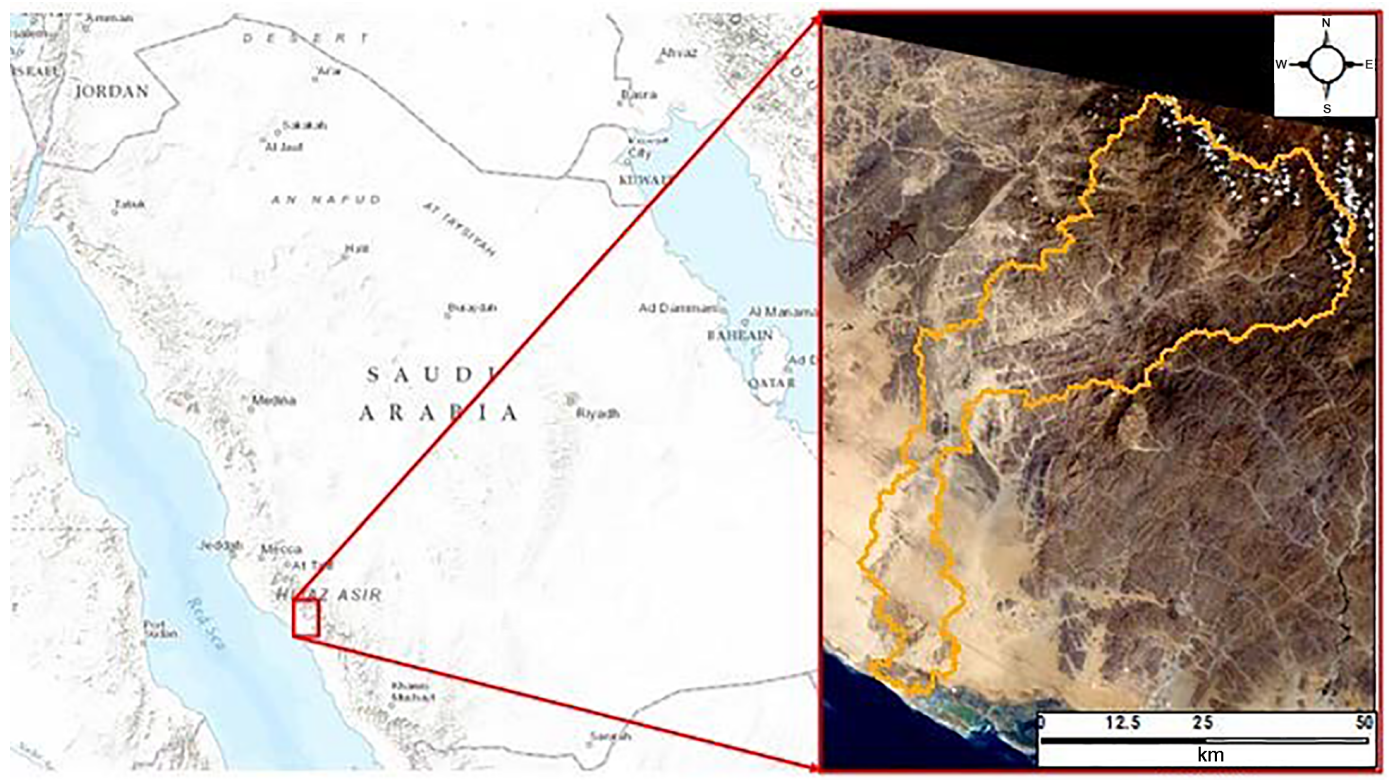

Figure 1. Location of the study area (Elhag, 2016).

- Interpolation (Stoer and Bulirsch, 1980):

$$
Z_{x}\left(X_{o}\right)=\sum_{i=1}^{n} \lambda_{i} x Z\left(x_{i}\right)
$$

where $Z_{x}\left(x_{o}\right)$ is the interpolated value of variable $Z$ at location $X_{o}, Z\left(x_{i}\right)$ are values measured at location $x_{i}$, and $\lambda i$ are weighed coefficients calculated based on the semivariogram.

- Trend and random error (Johnson and Riess, 1982):

$Z(S)=\mu(S)+\varepsilon(S)$

where $S$ stands for the location of the prediction location, $Z(S)$ is the variable being predicted (total extractable heavy metal concentration), $\mu(S)$ is the deterministic trend, and $\varepsilon(S)$ is the spatially autocorrelated random error.

\subsection{Morphometric parameters}

Based on the scholarly works of Horton (1945), Schumm (1963), Strahler (1964) and others, several morphometric parameters were used and computed utilizing the ASTER GDEM in a GIS environment. Consequently, watershed delineation, stream network identification, drainage frequency, drainage density, shape, elongation ratio, circularity ratio and form factor were computed and evaluated using the ASTER GDEM at $30 \mathrm{~m}$ spatial resolution. The methodologies adopted for the evaluation and computation of morphometric features are given in Table 1.

\subsection{Supervised classification}

Remote sensing data, acquired on 10 June 2013, were obtained from Landsat Operational Land Imager (OLI-8). Typical atmospheric and radiometric corrections and spatial resolution enhancement were implemented for each band individually. Furthermore, supervised classification was implemented using a support vector machine (SVM) classifier for better classification of results (Psilovikos and Elhag, 2013). The final step in the digital image analysis was the evaluation of the accuracy of the computer-derived classification results. These results are often expressed in tabular form, known as a confusion matrix (Elhag et al., 2013). The SVM classifier is implemented as

$K\left(x_{i}, x_{j}\right)=\tanh \left(g x_{i}^{T} x_{j}+r\right)$,

where $g$ is the gamma term in the kernel function for all kernel types except linear and $r$ is the bias term in the kernel function for the polynomial and sigmoid kernels.

\section{Results and discussion}

Quantitative evaluation of the watershed through the analysis of morphometric parameter can provide significant information about the hydrological characteristics of rocks which are exposed within the basin. The nature of drainage of a basin reveals reliable information about the permeability of the rocks and the yield of the basin.

Evaluation of drainage characteristics and other morphometric parameters of the Yalamlam Basin has been undertaken to calculate the parameters and construct the topology 
Table 1. Summary of the implemented morphometric features.

\begin{tabular}{llll}
\hline Item & Morphometric feature & Equation & Citation \\
\hline 1 & Stream length $\left(L_{u}\right)$ & Length of the stream & Horton (1945) \\
2 & Stream length ratio $\left(R_{\mathrm{L}}\right)$ & $R_{\mathrm{L}}=L_{u} /\left(L_{u}+1\right)$ & Horton (1945) \\
3 & Form factor $\left(F_{\mathrm{f}}\right)$ & $F_{\mathrm{f}}=A / L^{2}$ & Horton (1945) \\
4 & Drainage frequency $\left(F_{\mathrm{d}}\right)$ & $F_{\mathrm{d}}=N_{u} / A$ & Horton (1945) \\
5 & Drainage density $\left(D_{\mathrm{d}}\right)$ & $D_{\mathrm{d}}=L_{u} / A$ & Horton (1945) \\
6 & Drainage texture $(T)$ & $T=D_{\mathrm{d}} * F_{\mathrm{d}}$ & Smith (1950) \\
7 & Bifurcation ratio $\left(R_{\mathrm{b}}\right)$ & $\left(R_{\mathrm{b}}\right)=N_{u} /\left(N_{u}+1\right)$ & Schumm (1956) \\
8 & Elongation ratio $\left(R_{\mathrm{e}}\right)$ & $R_{\mathrm{e}}=D / L$ & Schumm (1956) \\
9 & Mean bifurcation ratio $\left(R_{\mathrm{bm}}\right)$ & $R_{\mathrm{bm}}=$ average of bifurcation ratios & Strahler $(1957)$ \\
10 & Relief $(R)$ & $R=H-h$ & Hadley and Schumm $(1961)$ \\
11 & Relief ratio $\left(R_{\mathrm{r}}\right)$ & $R_{\mathrm{r}}=R / L$ & Schumm (1963) \\
12 & Stream order $\left(S_{\mathrm{o}}\right)$ & Hierarchical rank & Strahler (1964) \\
13 & Stream number & Order-wise no. of streams & Strahler (1964) \\
14 & Mean stream length $\left(L_{\mathrm{sm}}\right)$ & $L_{\mathrm{sm}}=L_{u} / N_{u}$ & Strahler $(1964)$ \\
15 & Circularity ratio $\left(R_{\mathrm{c}}\right)$ & $R_{\mathrm{c}}=4 \pi A / P^{2}$ & Strahler $(1964)$ \\
\hline
\end{tabular}

Abbreviations: $A$, the area of the basin $\left(\mathrm{km}^{2}\right) ; D_{\mathrm{d}}$, drainage density; $F_{\mathrm{f}}$, form factor; $F_{\mathrm{s}}$, stream frequency; $L$, basin length $(\mathrm{km}) ; L_{\mathrm{sm}}$, mean stream length; $L_{u}+1$, the total stream length of its next higher order $u ; L_{u}$, the total stream length of order $u ; N_{u}+1$, number of stream segments of the next higher order; $N_{u}$, the number of stream segments of order $u ; P$, perimeter $(\mathrm{km}) ; R_{\mathrm{b}}$, bifurcation ratio; $R_{\mathrm{c}}$, circularity ratio; $R_{\mathrm{e}}$, elongation ratio; RL, stream length ratio; and $T$, drainage texture; $\pi=3.14$

of the basin. Different types of areal and linear aspects and their characteristics have been calculated, such as basin area $(\mathrm{A})$, basin length $(\mathrm{L})$, basin perimeter $(\mathrm{P})$, bifurcation ratio $\left(R_{\mathrm{b}}\right)$, elongation ratio $\left(R_{\mathrm{e}}\right)$, circularity ratio $\left(R_{\mathrm{c}}\right)$, drainage frequency $\left(F_{\mathrm{d}}\right)$ and drainage density $\left(D_{\mathrm{d}}\right)$.

\subsection{Stream order $\left(S_{0}\right)$ and stream number}

The lower Yalamlam Basin encompasses the basin mega-fan, which is formed by ancient and modern radial drainage patterns in the study area. The channel of this area is characterized by higher sinuosity, decreased widths and lesser discharge capacity than numerous traverse paleo-alluvial channels (Bahrawi et al., 2016). Therefore, the stream ordering of the study area has been ranked based on the Strahler (1964) method and demonstrated in Table 2.

\subsection{Bifurcation ratio}

The bifurcation ratio was calculated as the number of streams of an order to the number of the streams of the next higher order. The values vary from 2.0 to 4.42 for the Yalamlam stream basin, which also indicates the maximum structural influences (Strahler, 1964). After the calculation of the bifurcation ratio, the average value is calculated; the mean bifurcation ratio is 3.84 for the basins. The value also indicates that the drainage pattern has been affected by structural disturbances within the basin. The obtained number for the bifurcation ratio varies from one order to another. Such variation is interpreted as the result of irregularities in the lithological and geological development within the watershed. The values of the bifurcation ratio and mean bifurcation ratio are shown in Table 3.

\subsection{Drainage texture and drainage density}

Drainage density is an expression of spacing and the distribution of channels as proposed by Horton (1932), measuring the total length of the streams of all orders as calculated per unit area. The relative relief and slope gradient of the river basin primarily control the stream density. The stream density of the watershed has been calculated and is shown in Table 3 . The drainage density value is 0.92 in the study basin. The drainage density has been classified into five kinds of drainage texture as proposed by Smith (1950).

Drainage density values are classified as follows: more than 8 , very fine drainage texture; $8-6$, fine; between 6 and 4 , moderate; 4-2, coarse; and less than 2, very coarse. The observer drainage texture is 0.138 , which indicates resistant permeable rock with a moderate infiltration rate and moderate relief (Bahrawi et al., 2016). The value of the variation of drainage texture depends on different types of natural factors, i.e., rainfall and other climatic characteristics, rock type, soil type, vegetation characteristics, permeability, relief, and infiltration capacity within the watershed. The relationship between the hydrological features and the geological structures is estimated to be with a high drainage density caused by the mountainous relief in the basin. The lower drainage density value reveals that the region is composed of permeable subsurface material and low-relief, dense vegetal cover, which results in an increase in infiltration capacity in the basin. The high drainage density value indicates mountainous relief, thin vegetation and impermeable subsurface material, and highly resistant rock types in the river basin. 
Table 2. Stream network order based on the Strahler method.

\begin{tabular}{rlrrrrr}
\hline & Strahler & Cnt_Strahler & $R_{\mathrm{b}}$ & $\mathrm{Nu}-\mathrm{r}$ & $R_{\mathrm{b}} \cdot \mathrm{Nu}-\mathrm{r}$ & Sum_Length \\
\hline 1 & 598 & & & & 872.847 \\
2 & 135 & 4.42963 & 733 & 3246.919 & 452.488 \\
3 & 22 & 6.13636 & 157 & 963.409 & 237.306 \\
& 4 & 6 & 3.66667 & 28 & 102.667 & 112.047 \\
& 5 & 2 & 3.00000 & 8 & 24.000 & 54.635 \\
& 6 & 1 & 2.00000 & 3 & 6.000 & 58.259 \\
\hline \multirow{2}{*}{ Sum } & 764 & 19.232659932 & 929 & 4342.99427609428 & 1787.582302 \\
\hline \multirow{2}{*}{ Mean } & & 3.847 & & 4.675 & \\
\hline
\end{tabular}

Table 3. Wadi Yalamlam morphometric features.

\begin{tabular}{lrl}
\hline Parameters & Descriptions & Remarks \\
\hline Basin area $\left(\mathrm{km}^{2}\right)$ & 1940.3 & The basin area is too large \\
Basin length $(\mathrm{km})$ & 60.56 & Basin length is very high \\
Basin perimeter $(\mathrm{km})$ & 417 & High basin perimeter \\
Elongation ratio & 0.14 & Elongated \\
Form factor & 0.06 & Elongated shape and flatter peak flow \\
Circularity ratio & 0.08 & Strongly elongated and heterogeneous geological structure \\
Drainage frequency & 0.34 & Low stream frequency \\
Drainage density & 0.92 & Drainage density is considerably high \\
Drainage texture & 0.138 & Highly resistant permeable rock with moderate infiltration rate \\
\hline
\end{tabular}

\subsection{Drainage frequency}

Drainage frequency, or stream frequency, is calculated as the total number of streams per unit area of all stream orders proposed by Horton (1932). The correlation value of drainage density and stream frequency plays a positive role in the basin, which suggests that the number of streams and population increase with the increase in drainage density. The observed value of stream frequency is about 0.34 for the watershed, showing a highly positive connection with stream density; see Table 3.

\subsection{Elongation ratio}

The elongation ratio is calculated as the ratio between the maximum length of the basin and the diameter of a circle which is fitted in the same basin area, as proposed by Schumm (1956). The elongation ratio value generally varies between 0.6 and 1.0, with a wide variety of geological conditions and climatic characteristics. According to Strahlar (1964), values close to 1.0 represent a region of very low relief with few structural influences, and values ranging from 0.8 to 0.6 are generally associated with a much steeper slope and high relief. The values of the elongation ratio can be categorized into three groups: less than 0.7 indicates an elongated basin shape, values of 0.8 to 0.9 represent an oval shape, and values more than 0.9 represent a circular shape. Thus, the elongated ratio of the study area is 0.14 , which suggests that the basin shape is a much more elongated type (Table 3) of basin over which there is a considerable structural influence.

\subsection{Circularity ratio}

According to Miller (1953), the circularity ratio is the ratio between the area of a circle which is fitted in the basin perimeter and the total basin area. The circularity ratio is much more influenced by geological structure, relief, slope, climate, frequency and length of stream, and land use/land cover within the basin. The basin circularity ratio is 0.08 , which shows that the basin is strongly elongated and has heterogeneous geological structure and materials. The observed values also indicate high runoff capacity and low permeability capacity of subsoil and subsurface soil along the basin area (Table 3).

\subsection{Form factor}

Horton (1932) defines the form factor as the ratio between the square of the basin length and basin area. The values of form factor represent the flow intensity of the study area. Generally, the elongation shape and the values of form factor have a negative relationship, which means that a smaller value indicates a more elongated shape of the basin. The values should always be lower than 0.7854; a higher value of form factor represents higher peak flows of a higher period. The observed value of form factor is 0.06 for the Yalamlam 
Table 4. Wadi Yalamlam land cover classifications.

\begin{tabular}{lrr}
\hline Land cover category & Area $\left(\mathrm{km}^{2}\right)$ & Percentage $(\%)$ \\
\hline Vegetation & 82.7 & 4.26 \\
Alluvial deposit & 803.3 & 41.4 \\
Bare rocks & 1054.3 & 54.3 \\
\hline Total & 1940.3 & 100 \\
\hline
\end{tabular}

watersheds, which indicates an elongated shape of the basin (Table 3). Therefore, the lower values and elongated basin shape indicate that the watershed has a flatter peak flow of shorter duration.

\subsection{Relief and relief ratio of the watershed}

Relative relief is the difference between the highest and lowest elevation of the watershed. The relief ratio is the ratio between relative relief and the maximum length of the basin as proposed by Schumm (1956). It can analyze the steepness of the basin and evaluate the intensity of the erosion process in the study area. Here the relief ratio is 4.17 , which indicates that most of the designated basin is situated along the rough, mountainous slope and is much narrower in the lower areas.

\subsection{Slope map}

Slope is the ratio between horizontal and vertical surface of a region, which can be expressed by the percentage and degree. It was found that the most of the area (i.e., the upper middle part) of Yalamlam watershed is classified as steep, very steep and very high steep slopes, which indicates that the area has very mountainous topography. The main channel slope of the basin has a gentle slope (0.042), meaning flat topography that is excellent for groundwater management through favoring infiltration.

\section{Geohydrological inferences from morphometric evaluation}

The classification of remote sensing data was to quantify the area of all alluvial deposits in the bare rock area within the designated study area as illustrated in Fig. 2. Table 4 indicates that the area of the alluvial deposits is roughly equal to the bare rock area, which means that the watershed is likely to be used for rainwater harvesting (Elhag, 2014 and Elhag and Bahrawi, 2014a).

The quantitative morphometric evaluation has considerable utility for watershed delineation, water and soil conservation, and their management for future sustainability. The morphometric analysis of the Yalamlam Basin shows that the watershed has a narrow, elongated shape and very high mountainous relief. The planning for runoff and artificial recharge of the area has been chosen based on small-scale

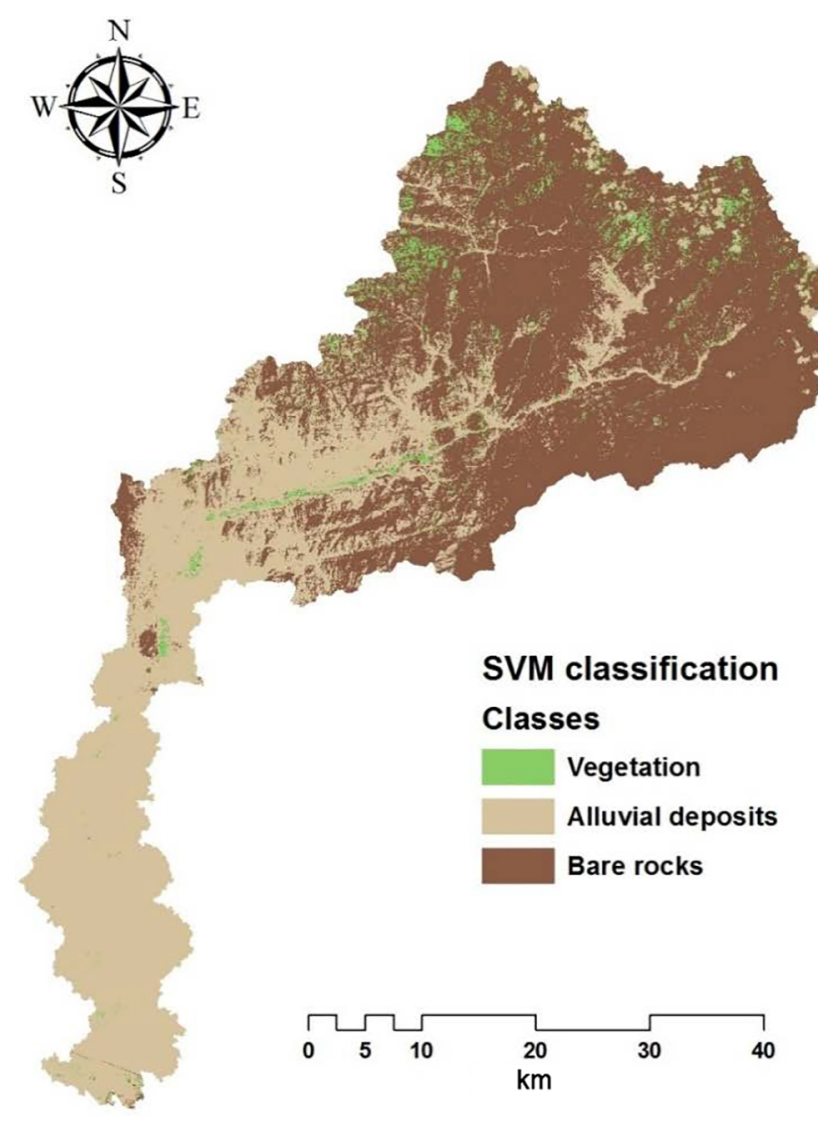

Figure 2. Supervised classification of the Yalamlam Basin.

topographical maps and low relief (gentle slope) in the lower area of the basin. Also, drainage morphometry plays a positive role in GIS and remote sensing techniques by selecting artificial recharge sites and creating a demand storage point in the mountainous region with the basin. In addition, if the morphometric information is integrated with other hydrological parameters of the river basin, the strategy for water harvesting and recharging measures gives a better plan for groundwater management and development for the future.

The drainage pattern of the basin is sub-dendritic and radial in nature. The pattern was affected by more or less heterogeneous structural and lithological characteristics. In addition, high drainage density is observed all over the watershed along with very high relief and impermeable subsoils and land rock substratum, as well as mountainous terrain slope. Nevertheless, lower riparian areas have low drainage density, which is favorable for the identification of water storage areas and potential groundwater zones. However, slope plays a significant role in determining the relationship between infiltration rate and runoff velocity, where infiltration rate is inversely controlled by regional slope. Therefore, all evaluated parameters are more important for the analysis of future water availability in the study region. 
Results obtained from previous scholarly work of Şen (1995) showed that the average transmissivity values calculated within the study area range from 91 to $147 \mathrm{~m}^{2}$ day $^{-1}$. However, the transmissivity values increase sharply in the downstream area, ranging between 267 and $731 \mathrm{~m}^{2}$ day $^{-1}$ (average of $500 \mathrm{~m}^{2} \mathrm{day}^{-1}$ ). Such findings support the hypothesis that the aquifer is of high potential therein. Nonetheless, the hydraulic conductivity values calculated for the Yalamlam Basin attain high hydraulic conductivity $\left(16 \mathrm{~m} \mathrm{day}^{-1}\right)$ due to more permeable alluvial deposits (Sen, 1995; Elhag and Bahrawi, 2014b, c).

\section{Conclusions}

Our evaluation of hydrological characteristics of the Yalamlam watershed confirms that the area has high relief and its shape is elongated in nature. The stream network of the watershed is essentially of dendritic type in the lower portion, which indicates a lack of structural influences and homogeneity of textural characteristics, but the upper portion of the watershed is highly influenced by tectonic and structural activity due to the parallel pattern of the drainage network. The drainage characteristics of the basin help to understand the different types of terrain parameters, i.e., runoff, infiltration capacity and the nature of the bedrock etc. The drainage density and frequency of the drainage basin are low, which indicates a high permeability rate and well-drained capacity of the subsurface formation. A variety of basic and derived parameters reveal the importance of the water recharge areas, and measures can be undertaken for the soil conservation structures and water resource management. Therefore, watershed analysis using remote sensing data, GDEM data and GIS techniques is an efficient, precise tool for the understanding of any terrain attributes such as surface runoff, the nature of bedrock, and infiltration capacity; this helps in better understanding drainage evolution and management of groundwater potential, the status of landforms, and their characteristics for watershed management and planning. The study should be useful for water as well as natural resource management of any terrain at the watershed level. For sustainable water resource management and watershed development, decision makers and planners can use these kinds of hydrological analyses.

Data availability. Data are available for free from the USGS website (https://earthexplorer.usgs.gov/).

Competing interests. The authors declare that they have no conflict of interest.

Acknowledgements. This article was funded by the Deanship of Scientific Research (DSR) at King Abdulaziz University, Jeddah.
The authors therefore thank DSR for technical and financial support.

Edited by: Andrea Benedetto

Reviewed by: Silvena Boteva and two anonymous referees

\section{References}

Bahrawi, J. A., Elhag, M., Aldhebiani, A. Y., Galal, H. K, Hegazy, A. K., and Alghailani, E.: Soil Erosion Estimation Using Remote Sensing techniques in Wadi Yalamlam basin, Saudi Arabia, Advances in Materials Science and Engineering, 2016, 9585962, https://doi.org/10.1155/2016/9585962, 2016.

Elhag, M.: Remotely sensed vegetation indices and spatial decision support system for better water consumption Regime in Nile Delta. A case study for rice cultivation suitability map, Life Science Journal, 11, 201-209, 2014.

Elhag, M.: Characterization of a Typical Mediterranean Watershed Using Remote Sensing Techniques and GIS Tools, Hydrology: Current Research, 6, 197-204, 2015.

Elhag, M.: Evaluation of Different Soil Salinity Mapping Using Remote Sensing Techniques in Arid Ecosystems, Saudi Arabia, Journal of Sensors, 2016, 96175-96175, 2016.

Elhag, M. and Bahrawi, J.: Cloud Coverage Disruption for Groundwater Recharge Improvement Using Remote Sensing Techniques in Asir Region, Saudi Arabia, Life Science Journal, 11, 192-200, 2014a.

Elhag, M. and Bahrawi, J.: Conservational Use of Remote Sensing Techniques for a Novel Rainwater Harvesting in Arid Environment, Environ. Earth Sci., 72, 4995-5005, 2014b.

Elhag, M. and Bahrawi, J.: Potential Rainwater Harvesting Improvement Using Advanced Remote Sensing Applications, The Scientific World Journal, 2014, 806959, https://doi.org/10.1155/2014/806959, 2014c.

Elhag, M. and Bahrawi, J. A.: Realization of daily evapotranspiration in arid ecosystems based on remote sensing techniques, Geosci. Instrum. Method. Data Syst., 6, 141-147, https://doi.org/10.5194/gi-6-141-2017, 2017.

Elhag, M., Psilovikos, A. and Sakellariou, M.: Detection of Land Cover Changes for Water Recourses Management Using Remote Sensing Data over the Nile Delta Region, Environment, Development and Sustainability, 15, 1189-1204, 2013.

Farr, T. G. and Kobrick, M.: Shuttle radar topography mission produces a wealth of data, American Geophysical Union, 81, 583585, 2000.

Gotway, C. A., Ferguson, R. B., Hergert, G. W., and Peterson, T. A.: Comparison of kriging and inverse distance methods for mapping soil parameters, Soil Sci. Soc. Am. J., 60, 1237-1247, 1996.

Grohmann, C. H., Riccomini, C., and Alves, F. M.: SRTM-based morphotectonic analysis of the Pocos de Caldas alkaline Massif, southeastern Brazil, Comput. Geosci., 33, 10-19, 2007.

Hadley, R. F. and Schumn, S. A.: Sediment sources and drainage basin characteristics in the upper Cheyenn River Basin, US Geological Survey, Water supply paper, 1531-B, 137-197, 1961.

Horton, R. E.: Erosional development of streams and their drainage basins; hydrophysical approach to quantitative morphology, U.S. Geological Survey Professional, p. 282A, 1945. 
Horton, R. E.: Drainage basin characteristics, Trans. Amer. Geophys. Union, 13, 350-361, 1932.

Johnson, L. W. and Riess, R. D.: Numerical Analysis, 2nd edn., Reading, MA: AddisonWesley, Chapter 1.3., 1982.

Leenaers, H., Okx, J. P., and Burrough, P. A.: Employing elevation data for efficient mapping of soil pollution on floodplain, Soil Use Manage., 6, 105-113, 1990.

Magesh, N., Chandrasekar, N., and Soundranayagam, J.: Morphometric evaluation of Papanasam and Manimuthar watersheds, parts of Western Ghats, Tirunelveli district, Tamil Nadu, India: a GIS approach, Environmental Earth Sciences, 64, 373-381, 2011.

Miller, V. C.: A Quantitative Geomorphologic Study of Drainage Basin Characteristics in the Clinch Mountain Area, Virginia and Tennessee, Project NR 389042, Tech Rept 3. Columbia University Department of Geology, ONR Geography Branch, New York, 1953.

Mueller, T. G., Pusuluri, N. B., Mathias, K. K., Cornelius, P. L., Barnhisel, R. I., and Shearer, S. A.: Map Quality for Ordinary Kriging and Inverse Distance Weighted Interpolation, Soil Sci. Soc. Am. J., 68, 2042-2047, 2004.

Panhalkar, S. S.: Hydrological modeling using SWAT model and geoinformatic techniques, Egypt, The Egyptian Journal of Remote Sensing and Space Science, 17, 197-207, 2014.

Pankaj, A. and Kumar, P.: GIS based morphometric analysis of five major sub-watershed of Song River, Dehradun district, Uttarakhand with special reference to landslide incidences, Journal of the Indian Society of Remote Sensing, 37, 157-166, 2009.

Psilovikos, A. and Elhag, M.: Forecasting of Remotely Sensed Daily Evapotranspiration Data over Nile Delta Region, Egypt, Water Resour. Manag., 27, 4115-4130, 2013.

Schloeder, C. A., Zimmerman, N. E., and Jacobs, M. J.: Comparison of methods for interpolating soil properties using limited data, Soil Sci. Soc. Am. J., 65, 470-479, 2001.
Schumm, S. A.: Evolution of drainage systems and slopes in badlands at Perth Amboy, New Jersy, National Geological Society of America Bulletin, 67, 597-646, 1956.

Schumm, S. A.: Sinuosity of alluvial rivers in the Great Plains, Bull. Geol. Soc. Am., 74, 1089-1100, 1963.

Sen, Z.: Wadi Hyrdology, CRC Press, Taylor and Francis, New York, 1995.

Smith, K. G.: Standards for grading texture of erosional topography, Am. J. Sci., 248, 655-668, 1950.

Sreedevi, P. D., Sreekanth, P. D., Khan, H. H., and Ahmed, S.: Drainage morphometry and its influence on hydrology in a semiarid region: using SRTM data and GIS, Environ. Earth Sci., 70, 839-848, 2013.

Stoer, J. and Bulirsch, R.: Introduction to Numerical Analysis, New York, Springer-Verlag, Chapter 2, 1980.

Strahler, A. N.: Quantitative Geomorphology of drainage basins and channel networks, in: Handbook of Applied Hydrology, edited by: Chow, V. T., Newyork; Mc Graw hill, Section 4-11, 1964.

Strahler, A. N.: Quantitative analysis of watershed geomorphology, Trans. Am. Geophys. Union, 38, 913-920, 1957.

Weibel, R.: A Typology of Constraints to Line Simplification, in: Advances in GIS Research II (7th International Symposium on Spatial Data Handling), edited by: Kraak, M. J. and Molenaar, M., London, Taylor and Francis, 533-546, 1997.

Weller, U., Zipprich, M., Sommer, M., zu Castell, W., and Wehrhan, M.: Mapping clay content across boundaries at the landscape scale with electromagnetic induction, Soil Sci. Soc. Am. J., 71, 1740-1747, 2007.

Wollenhaupt, N. C., Wolkowski, R. P., and Clayton, M. K.: Mapping soil test phosphorus and potassium for variable-rate fertilizer application, J. Prod. Agric., 7, 441-448, 1994. 